Pak. j. sci. ind. res. Ser. B: biol. sci. 2019 62B(2) 88-96

\title{
Synergistic Effect of Fungus Metarhizium anisopliae and Slow Acting Toxicants Fipronil and Imidacloprid against Subterranean Termites
}

\author{
Ambash Riaz ${ }^{\text {ab }}$, Khalid Zamir Rasib and Shahid Raza ${ }^{\mathrm{b}}$ *

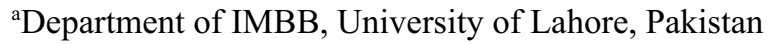 \\ ${ }^{b}$ Faculty of Life Sciences, University of Central Punjab, Lahore, Pakistan \\ (received May 4, 2017; revised December 28, 2018; accepted January 14, 2019)
}

\begin{abstract}
Three experiments were conducted to check Coptotermes heimi termites mortality in different conditions. In first experiment, two termiticides; fipronil and imidacloprid of specific formulation $25 \mathrm{EC}$ and 5\% SC, respectively, were used. Different concentration dilutions were prepared and termites' mortality assay was performed. Both formulations gave $100 \%$ termites mortality on their highest ppm concentration after one week. Second experiment was based on different spore concentrations of Metarhizium anisopliae that were applied on worker termites to check the lethal concentration of fungi. It was observed that spore concentration showed direct relationship with termites' mortality which means, as the spore concentration increases, termite mortality also increases. Last experiment was conducted to check the synergistic effect of M. anisopliae and termiticides. The fungus was used in combination with termiticides, fipronil and imidacloprid, separately. The rate of mortality of termites which exposed to imidacloprid/fipronil and M. anisopliae simultaneously was higher than mortality of termites exposed to either treatment alone.
\end{abstract}

Keywords: Coptotermes heimi, fipronil, imidacloprid, synergistic effect, Metarhizium anisopliae

\section{Introduction}

Termites are social insects with labor divisions between the different caste of individuals: soldiers, reproductive adults and workers (Grimaldi and Engel, 2005). They live in colonies by forming networks that can be both underground and above ground. Subterranean termites feed on cellulose material present in wood thus it can cause serious economic damage to buildings and agricultural plants (Song and $\mathrm{Hu}, 2006$ ). They can be found worldwide especially in the tropical and sub-tropical regions. Termites also have some symbiotic associations with gut microbes linked to digestive processes (Dietrich and Brune, 2016). The prominent characteristic of termites are their destructive tendency which forces scientists to get themselves involved in finding its environment friendly solutions. Termite symbiotic systems host component adds stability to the digestive process with the help of some contributing enzymes by maintaining a favorable gut microenvironment for digestion process (Tokuda et al., 2014; Sethi et al., 2013; Scharf et al., 2011; Tartar et al., 2009).

In the past, organochlorine insecticides were assumed to be effective for the termites and other pest control. One application around a building could avoid termites

*Author for correspondence; E-mail: dr.raza03@gmail.com attack over 30 years (Cowie et al., 1989). Even now a days, efforts to avoid subterranean termite attack inside building have heavily depended on the applications of liquid termiticide. Liquid termiticides are projected to provide a defensive barrier between the structure over ground and the termites in the soil ( $\mathrm{Su}$ and Scheffrahn, 1990a). Though liquid termiticides have ability to overpower termite populations, they also have many limitations. First, excess use of toxicants causes environmental concerns as well as termites can also develop resistance against these toxicants. Furthermore, termites can also prevent their contacts with the toxicants by moving from one place to another (Zoberi, 1995). Secondly, termite population living away from treated area may or may not be affected by these chemicals (Forschler, 1994). For example, large populations of termites may continue its infestation in the soil around a building, although records showed chemicals were applied (Grace et al., 1989). Third, chemicals used for soil treatment around or under the buildings can only able to kill a small portion of the termites ( $\mathrm{Su}$ and Scheffrahn, 1990b). If the buildings are not properly treated, the remaining large portion of termites will continue to hunt and attack the buildings. Fourth, the efficiency of the termiticides can be affected by various environmental factors e.g. various biotic components and soil types (Smith and Rust, 1993). 
Due to the above problems associated with the use of chemicals against termites, interest has been focused on the advances of novel biological control methods to control subterranean termites' infestation (Grace and Zoberi, 1992). The use of fungi as biological control agents is an attractive alternative to the use of chemicals. Many authors have reported termite and fungi interaction (Zoberi, 1979). Biological control of termites by using fungi seems to be an attractive option because of several reasons: (1) both fungi and termites share same environmental conditions (2) their non-repellant nature toward termites, safety to non-target organism and the self replicating nature of fungi (Zoberi and Grace, 1990).

Studies have showed range of evolutionary termites behavioral, physiological, and immunological mechanism resulting in an efficient individual and social immunity (Chouvenc and Su, 2010; Rosengaus et al., 2010). The social behavior of these insects such as avoidance of healthy termites from infected termite and their grooming with nest mates, is considered as the major reason behind unsuccessfulness of these pathogens under field (Rath, 2000). Because of the environmental concerns and shortage of some effective chemical termiticides in the market, scientists are again interested in biological control of termites in recent years (Connick et al., 2001; Osbrink et al., 2001). Metarhizium anisopliae is usually recommended for practical control of termites as a bio insecticide because it does not show any effect on human and higher organisms and almost all species of termites can be infected by this fungus. Their conidia are easy to store, and they can survive more than 18 months in termite nests (Milner and Staples, 1996).

Considering all the problems as mentioned above, the premise of this study is to check termite's mortality rates on different parameters. Related objective of the study includes: Mortality bioassays of termites using fipronil and imidacloprid, effect of different concentrations of fungus Metarhizium anisopliae on constant size group termite, and effect of fungus Metarhizium anisopliae in combination with slow acting toxicants fipronil and imidacloprid against termites.

\section{Materials and Methods}

Collection and identification of termites. Termites were collected from infested trees of Populus euramericana located at the vicinity of Forman Christian College, Lahore. Coptotermes heimi (Wasmann) was identified using morphological keys for soldiers and workers (Snyder, 1954).
Maintenance of termites at controlled laboratory conditions. Termites were acclimatized at laboratory conditions at $25{ }^{\circ} \mathrm{C}$ and $70 \% \mathrm{Rh}$ prior to experimentations. Termites were fed on cellulose based food source (Whatmann filter paper) for three days in petriplates before experiments.

Culturing of Metarhizium anisopliae on selected media. Metarhizium anisopliae stock culture, 2-3 weeks old, was supplied by Entomology Laboratory at Forman Christian College, Lahore, Pakistan. The fungus was streaked on two different media; SDA and PDA at 27 or $30^{\circ} \mathrm{C}$ in the dark for $10-19$ days.

The media were prepared by dissolving $65 \mathrm{~g}$ of SDA and $39 \mathrm{~g}$ of PDA in $1 \mathrm{~L}$ of distilled water separately, followed by autoclaving (at $121^{\circ} \mathrm{C}$ at 15 psi pressure for $15 \mathrm{~min}$ ) of both media. Laminar flow was used to prepare SDA plates followed by incubation at $37^{\circ} \mathrm{C}$ for overnight to confirm that the plates are free of contamination. Collected fungal stocks were cultured on the plates and incubated at $25-30{ }^{\circ} \mathrm{C}$ for 3-5 days. Growth of Metarhizium anisopliae was compared on both media.

Experiment 1. Mortality bioassays using fipronil and imidacloprid. Two termiticides formulations i.e. fipronil $25 \mathrm{EC}$ and imidacloprid 5\% SC were used in this study. Petri dishes $(1.5 \mathrm{~cm}$ in height, $5.2 \mathrm{~cm}$ in diameter) provisioned with Whatman No. 1 filter paper of the same diameter served as treatment chambers. Petri dishes were treated with serial dilutions of imidacloprid $(15,7.5,3.75,1.87,0.93,0.46,0.23,0.11$, $0.05 \mathrm{ppm})$ and fipronil $(12,6,3,1.5,0.75,0.375,0.19$, $0.09,0.047 \mathrm{ppm}$ ) in water. Control treatment in this case was filter paper treated with water alone. Worker termites were released in each insecticide treated petri plate including control plate. The plates were placed in dark at room temperature. The experiment was conducted for a week and termites were examined every day.

Experiment 2. Effect of different concentrations of fungus Metarhizium anisopliae on constant size group termite. Six dilutions of $M$. anisopliae were prepared and spores were counted with the help of haemocytometer. Each dilution was distributed on different plates having worker termites. The experiment was conducted for a week and plates were examined every day. Dead termites were separated in another plate during everyday examination to check fungus growth on them. Plate without fungus dilution was served as control group. 
Experiment 3. Effect of fungus Metarhizium anisopliae in combination with slow acting toxicants fipronil and imidacloprid against termites. Constant spores concentration of $M$. anisopliae, $1.1 \times 10^{7}$ conidia $/ \mathrm{mL}$, were applied on termites in combination with three less toxic dilutions of termiticide formulations, fipronil 25 EC and imidacloprid 5\% SC. Petri plates having moistened Whatmann filter paper no 1 were treated with fungus first then applied by a dilution. Three replica of each dilution were prepared. Worker termites were released in each plate and their mortality was checked every day of the week. Dead infected termites were separated from healthy termites in separate petri plate and fungus growth was checked at the end of the experiment. Termite group in a petri plate without any termiticide and fungus served as control group.

\section{Results and Discussion}

Subterranean termites Coptotermes heimi (Wasmann) were collected in this study from the infested trees of Populas euramericana.

Culturing of Metarhizium anisopliae on selected media. Metarhizium anisopliae is an entomopathogenic fungus and has effect on wide range of insects including termites. The fungus growth was checked on two different media i.e., potato dextrose agar (PDA) and dextrose agar (SDA). Among these two media SDA showed more growth after 5 days of incubation (Fig. 1).

The colony morphology of Metarhizium anisopliae showed that it is a fast growing fungus and changes colour in its different levels of growth. White coloured colonies were obtained in first 3-4 days of growth which then turned to light yellow colour followed by yellow greenish colour and finally dark green colour having fully matured spores. The fungus had taken 1 week to turn from white to dark green. The dense masses of fungal colonies on petri dish gave velvety appearance (Fig. 2).

Experiment 1. Mortality bioassays using fipronil and imidacloprid. In case of imidacloprid, after 1 week experiment, $85,80,70,58,43,30,20.10$ and $8 \%$ mortality was observed at $15,7.5,3.75,1.87,0.93,0.46$, $0.23,0.11$ and 0.05 ppm, respectively (Fig. 3 ). On the other hand, in case of fipronil, at 12, 6, 3, 1.5, 0.75, $0.375,0.187,0.09$ and $0.047 \mathrm{ppm}, 100,90,74,60,54$, $46,30,20$ and $10 \%$ mortality was observed, respectively (Fig. 4).
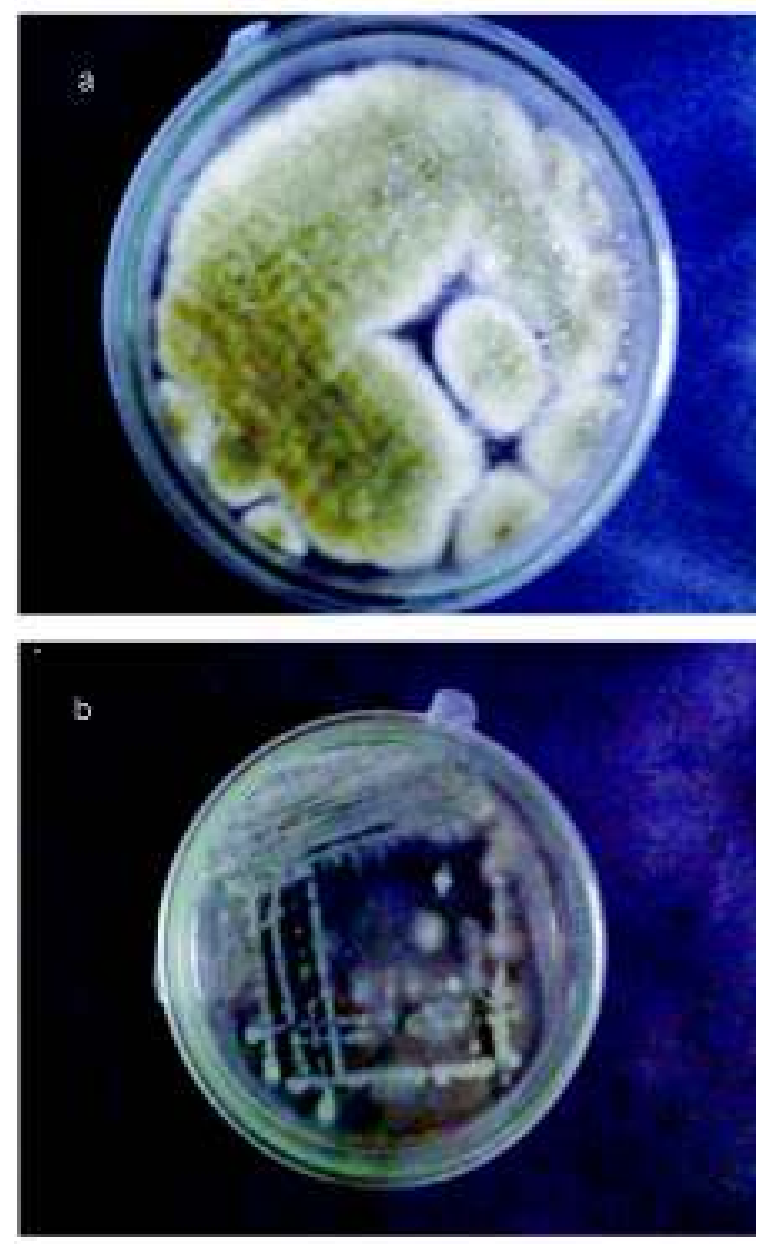

Fig. 1. Growth Metarhizium anisopliae on two media (a) SDA, (b) PDA.

Fipronil when experimented, proved to be more toxic product as compared with the other termiticide imidacloprid with $\mathrm{LC}_{50}$ significantly lower i.e., $0.56 \mathrm{ppm}$ (Table 1, Fig. 3). Imidacloprid was less toxic with $\mathrm{LC}_{50}$ i.e. $1.15 \mathrm{ppm}$ (Table 2) which indicated its heavy usage in the field to control termites. The results further showed that higher the $\mathrm{LC}_{50}$ of an insecticide greater the time it took to kill a termite population.

Table 1. Effect of fipronil on Coptotermes heimi

\begin{tabular}{llll}
\hline \hline Parameter & Estimate & $\begin{array}{l}\text { Standard } \\
\text { error }\end{array}$ & $\begin{array}{l}\text { 95\% Confidence } \\
\text { limit }\end{array}$ \\
\hline Intercept & 5.93 & 0.07 & $5.12-5.46$ \\
Slope & 1.17 & 0.09 & $0.93-1.41$ \\
\hline
\end{tabular}

$\mathrm{LC}_{50}=0.56 \mathrm{ppm}$. 


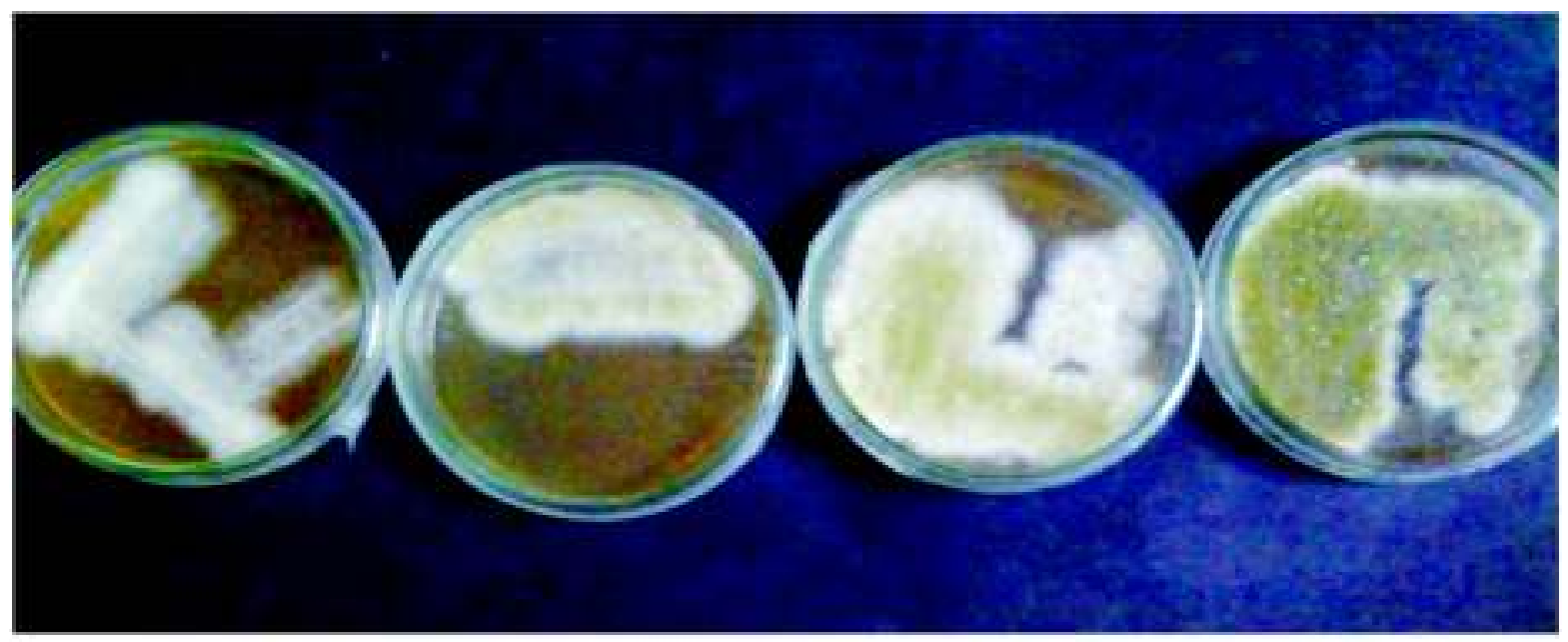

Fig. 2. Growth levels of Metarhizium anisopliae on SDA.

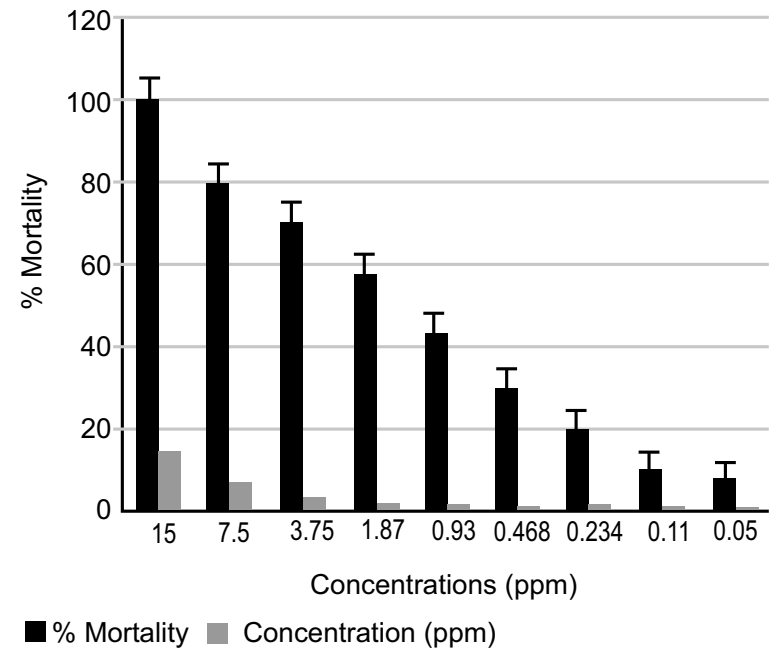

Fig. 3. \% mean mortality of Coptotermes heimi against imidacloprid after 1 week experiment.

Table 2. Effect of imidacloprid on Coptotermes heimi

\begin{tabular}{llll}
\hline \hline Parameter & Estimate & $\begin{array}{l}\text { Standard } \\
\text { error }\end{array}$ & $\begin{array}{l}\text { 95\% Confidence } \\
\text { limit }\end{array}$ \\
\hline Intercept & 4.93 & 0.07 & $4.76-5.09$ \\
Slope & 1.23 & 0.1 & $0.99-1.48$ \\
\hline \hline
\end{tabular}

$\mathrm{LC}_{50}=1.15 \mathrm{ppm}$.

Experiment 2. Effect of different concentrations of fungus Metarhizium anisopliae on constant size group termite. Different concentrations of M. anisopliae gave different mortality rates of termites. With the increase

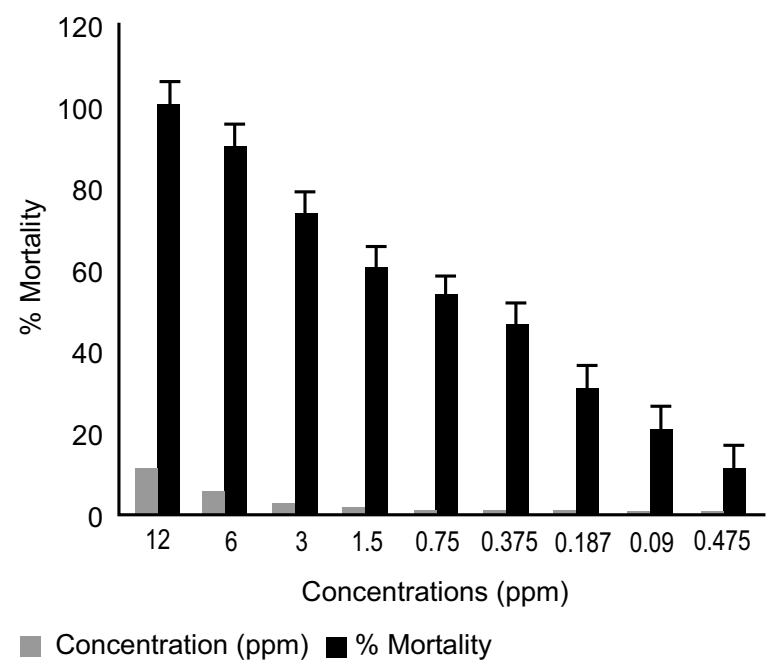

Fig. 4. Percentage mean mortality of Coptotermes heimi against fipronil after 1 week experiment.

of fungal spore concentration, termites' mortality also increased which shows a direct relationship between fungal spore concentration and mortality rate of termites. $100,90,70,60,50$ and $30 \%$ mortality was observed at the spores concentrations of $1.2 \times 10^{7}, 1.1 \times 10^{7}, 7.5 \times 10^{6}$, $5.4 \times 10^{6}, 2.5 \times 10^{6}$ and $1.4 \times 10^{6}$, respectively (Table 3, Fig. 5).

Experiment 3. Effect of fungus Metarhizium anisopliae in combination with slow acting toxicants fipronil and imidacloprid against termites. The effect of filter paper treated with low concentrations of imidacloprid and fipronil alone on termites was minimal. 
Table 3. Effect of six different concentrations (conidia/ $\mathrm{mL})$ M. anisopliae on termites' mortality (\%)

\begin{tabular}{ll}
\hline \hline $\begin{array}{l}\text { Fungi concentrations } \\
(\text { Conidia/mL) }\end{array}$ & $\begin{array}{l}\text { Termites mortality } \\
(\%)\end{array}$ \\
\hline $1.2 \times 10^{7}$ & $100^{*}$ \\
$1.1 \times 10^{7}$ & $90^{*}$ \\
$7.5 \times 10^{6}$ & $70^{*}$ \\
$5.4 \times 10^{6}$ & $60^{*}$ \\
$2.5 \times 10^{6}$ & $50^{*}$ \\
$1.4 \times 10^{6}$ & 30 \\
\hline \hline
\end{tabular}

M. anisopliae-Imidacloprid combination. The combined treatment of $M$. anisopliae and imidacloprid played major role in the termites' mortality. It was observed that imidacloprid increased susceptibility of termite to M. anisopliae. Mortality of termites resulted from combined treatment of M. anisopliae and imidacloprid was higher than mortality of termites exposed to either treatment alone. After 7 days of continuous exposure, mortality of termites exposed to the $1.1 \times 10^{7}$ conidia $/ \mathrm{mL}$ of M. anisopliae and $0.23 \mathrm{ppm}$ of imidacloprid (100\% mortality) was significantly higher than the termites exposed to either M. anisopliae or imidacloprid alone. Two way anova shows that the interaction between the variables is significant $(\mathrm{P}<0.05)$ (Table 4$)$.

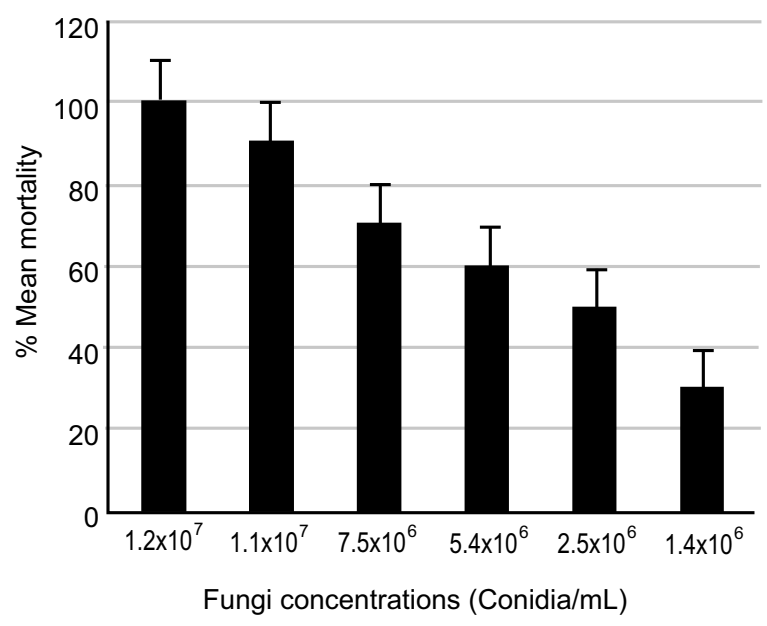

Mortality \%

Fig. 5. \% Mean Mortality of Coptotermes heimi against Metarhizium anisopliae after 1 week experiment.

M. anisopliae-Fipronil combination. The combination treatment of fipronil and M. anisopliae played an important role in the mortality of termites. 10, 20 and $30 \%$ mortality of termites was obtained on first day of experiment at $0.05,0.09$ and $0.18 \mathrm{ppm}$ concentrations, respectively, while $100 \%$ mortality of termites exposed to $0.05,0.09$ or $0.18 \mathrm{ppm}$ of fipronil after 7 days of

Table 4. Effect of different concentrations of imdacloprid at fixed level of M. anisopliae against Coptotermes heimi after one week exposure

\begin{tabular}{|c|c|c|c|c|c|}
\hline \multirow[t]{2}{*}{ Days } & \multirow{2}{*}{$\begin{array}{l}\text { M. anisopliae } \\
\text { concentration } \\
\text { (conidial } / \mathrm{mL} \text { ) }\end{array}$} & \multicolumn{4}{|c|}{$\%$ Mortality (mean $\pm \mathrm{SD})$ at concentration of imidacloprid $(\mathrm{ppm})$} \\
\hline & & 0 & 0.05 & 0.11 & 0.23 \\
\hline \multirow[t]{2}{*}{1} & 0 & $0.0 \pm 0.0$ & $0.1 \pm 0.13$ & $0.17 \pm 0.66$ & $0.29 \pm 0.43$ \\
\hline & $1 \times 10^{7}$ & $0.0 \pm 0.0$ & $10.00 \pm 3.00$ & $20.00 \pm 2.65^{*}$ & $10.00 \pm 3.61$ \\
\hline \multirow[t]{2}{*}{2} & 0 & $0.0 \pm 0.0$ & $0.9 \pm 1.8$ & $1.4 \pm 2.1$ & $2.43 \pm 1.6$ \\
\hline & $1 \times 10^{7}$ & $0.0 \pm 0.0$ & $30.00 \pm 5.00$ & $40.00 \pm 3.61$ & $40.00 \pm 4.36^{*}$ \\
\hline \multirow[t]{2}{*}{3} & 0 & $0.0 \pm 0.0$ & $2.5 \pm 2.1$ & $3.9 \pm 2.5$ & $5.1 \pm 2.0$ \\
\hline & $1 \times 10^{7}$ & $0.1 \pm 0.1$ & $40.00 \pm 2.65$ & $50.00 \pm 10.54$ & $60.00 \pm 3.61 *$ \\
\hline \multirow[t]{2}{*}{4} & 0 & $0.0 \pm 0.0$ & $6.3 \pm 3.7$ & $7.5 \pm 2.7$ & $8.9 \pm 4.4$ \\
\hline & $1 \times 10^{7}$ & $0.2 \pm 0.1$ & $50.00 \pm 5.57$ & $60.00 \pm 4.58$ & $70.00 \pm 6.24^{*}$ \\
\hline \multirow[t]{2}{*}{5} & 0 & $0.0 \pm 0.0$ & $10.2 \pm 4.1$ & $14.4 \pm 4.7$ & $17.3 \pm 3.9$ \\
\hline & $1 \times 10^{7}$ & $0.2 \pm 0.1$ & $70.00 \pm 5.57$ & $70.00 \pm 8.54$ & $80.00 \pm 7.02 *$ \\
\hline \multirow[t]{2}{*}{6} & 0 & $0.0 \pm 0.0$ & $19.8 \pm 2.2$ & $21.5 \pm 3.2$ & $23.4 \pm 4.5$ \\
\hline & $1 \times 10^{7}$ & $0.4 \pm 0.1$ & $80.00 \pm 4.04$ & $90.00 \pm 5.00 *$ & $90.00 \pm 4.58$ \\
\hline \multirow[t]{2}{*}{7} & 0 & $0.0 \pm 0.0$ & $26.4 \pm 4.2$ & $29.1 \pm 3.8$ & $33.2 \pm 4.9$ \\
\hline & $1 \times 10^{7}$ & $0.5 \pm 0.1$ & $100.00 \pm 0.00^{*}$ & $100.00 \pm 0.00^{*}$ & $100.0 \pm 0.00^{*}$ \\
\hline
\end{tabular}

$*=$ shows the level of significance at $0.05 \%$ level (Tukey's test). 
exposure. Two way anova shows that the interaction between the variables is significant $(\mathrm{P}<0.05)$ (Table 5).

Several studies have been carried out to test the efficiency of insecticides on different species of subterranean termite in different regions of the world. Beal (1986) in his ground board experiment, assessed different insecticides to analyze the control termite. It was reported that both Microtemeres obesi and Coptotermes heimi species do not penetrate soil treated with Permethrin (Su et al., 1982). Compared to the high mortality caused by fipronil, the toxicity of imidacloprid was both reduced and delayed. Thorne and Breisch (2001) analysed that the effect of imidacloprid was very minimum and negligible that the symptoms would disappear if termites were not exposed to the toxicant for a sufficient amount of time. They also observed delayed toxicity of imidacloprid and reported that death caused by imidacloprid took many days. Moreover, Haagsma (2003) analysed that complete mortality of Reticulitermes hesperus Banks need 14 days when they were exposed to 500 ppm imidacloprid for $2 \mathrm{~h}$.

Termites develop chemical mediated defenses against pathogen which include their ability to sense the toxins released by pathogenic fungi such as Beauveria and Metarhizium species. Because of this ability they avoid the contact with fungus spores or any toxin contaminated substrates (Grace, 1995). Rosengaus et al. (1999) describes that termites develop a protective immune system in response to exposure to fungal or bacterial pathogens. These findings demonstrate that termites have developed effective defense systems against pathogens.

Pathogenicity investigations were conventionally performed in petri dish containing only termites and the subjected pathogen. Researches on efficacy screenings (Rath and Tidbury, 1996; Wells et al., 1995; Zoberi and Grace, 1990) and the ecology of infection (Boucias et al., 1996; Zoberi, 1995) of several entomopathogens, including different isolates of $M$. anisopliae, against subterranean termites have been carried out almost completely in soil absence, thus opposing microbes. Milner and Staples (1996) observed over 90 isolates of $M$. anisopliae against Coptotermes spp. and Nasutitermes exitiosus workers and found that many isolates provoked over $80 \%$ mortality. Khan (1991) showed that among many mycopathogens, $M$. anisopliae was more virulent to Odontotermes brunneus. Gunner et al. (1994) observed that 21 isolates of M. anisopliae against Reticulitermes flavipes workers gave 80-100\% mortality within 3 days of treatment. Changjin et al. (2009) found that conidia from M. anisopliae var. dcjhyium were extremely virulent to Odontotermes formosanus, causing approximately $100 \%$ mortality after 3 days at a concentration of $3 \times 10^{8}$ conidia $/ \mathrm{mL}$.

Table 5. Effect of different concentration of fipronil at fixed level of $M$. anisopliae against Coptotermes heimi under laboratory conditions treated with filter paper for one week exposure

\begin{tabular}{|c|c|c|c|c|c|}
\hline \multirow[t]{2}{*}{ Days } & \multirow{2}{*}{$\begin{array}{l}\text { M. anisopliae concentration } \\
\text { (conidial } / \mathrm{mL} \text { ) }\end{array}$} & \multicolumn{4}{|c|}{$\%$ Mortality $($ mean \pm SD) at concentration of fipronil $(\mathrm{ppm})$} \\
\hline & & $\overline{0}$ & 0.05 & 0.09 & 0.18 \\
\hline \multirow[t]{2}{*}{1} & 0 & $0.0 \pm 0.0$ & $0.1 \pm 0.18$ & $0.2 \pm 0.67$ & $0.54 \pm 0.33$ \\
\hline & $1 \times 10^{7}$ & $0.0 \pm 0.0$ & $10.00 \pm 1.00$ & $20.00 \pm 1.82$ & $30.00 \pm 1.32 *$ \\
\hline \multirow[t]{2}{*}{2} & 0 & $0.0 \pm 0.0$ & $1.0 \pm 1.0$ & $1.7 \pm 1.0$ & $2.64 \pm 1.1$ \\
\hline & $1 \times 10^{7}$ & $0.1 \pm 0.1$ & $30.00 \pm 4.67$ & $40.00 \pm 2.62$ & $40.00 \pm 2.36^{*}$ \\
\hline \multirow[t]{2}{*}{3} & 0 & $0.0 \pm 0.0$ & $3.5 \pm 1.6$ & $4.6 \pm 2.1$ & $6.2 \pm 2.0$ \\
\hline & $1 \times 107$ & $0.1 \pm 0.1$ & $40.00 \pm 1.47$ & $50.00 \pm 3.71$ & $50.00 \pm 2.18^{*}$ \\
\hline \multirow[t]{2}{*}{4} & 0 & $0.0 \pm 0.0$ & $7.8 \pm 3.0$ & $9.5 \pm 2.4$ & $11.7 \pm 3.4$ \\
\hline & $1 \times 10^{7}$ & $0.2 \pm 0.1$ & $60.00 \pm 4.37$ & $60.00 \pm 2.51^{*}$ & $60.00 \pm 4.39$ \\
\hline \multirow[t]{2}{*}{5} & 0 & $0.0 \pm 0.0$ & $13.5 \pm 2.3$ & $15.7 \pm 4.1$ & $18.54 \pm 3.3$ \\
\hline & $1 \times 10^{7}$ & $0.3 \pm 0.1$ & $70.00 \pm 3.57$ & $70.00 \pm 6.04$ & $70.00 \pm 5.22 *$ \\
\hline \multirow[t]{2}{*}{6} & 0 & $0.0 \pm 0.0$ & $20.6 \pm 3.2$ & $23.1 \pm 4.0$ & $26.4 \pm 3.9$ \\
\hline & $1 \times 10^{7}$ & $0.3 \pm 0.1$ & $80.00 \pm 7.11$ & $80.00 \pm 4.54$ & $90.00 \pm 4.00^{*}$ \\
\hline \multirow[t]{2}{*}{7} & 0 & $0.0 \pm 0.0$ & $29.2 \pm 5.2$ & $31.9 \pm 4.4$ & $35.74 \pm 3.2$ \\
\hline & $1 \times 10^{7}$ & $0.5 \pm 0.1$ & $100.00 \pm 0.00 *$ & $100.00 \pm 0.00 *$ & $100.00 \pm 0.00 *$ \\
\hline
\end{tabular}

* = shows the level of significance at $0.05 \%$ level (Tukey's test). 
The combination of the toxicant imidacloprid and M. anisopliae killed termites at a faster rate than either experiment alone. Boucias et al. (1996) reported that introduction of Beauveria bassiana in soil, even at high dose gave $5 \%$ termite mortality after 2 weeks of continuous exposure. Synchronized exposure of subterranean termites to B. bassiana altered soil and filter paper discs soaked in a $0.001 \%$ imidacloprid solution increased susceptibility to the fungus. For instance, after 2 weeks of continuous exposure, mortality of termites exposed to $10^{5}$ conidia per gram and filter paper dipped in $0.001 \%$ of imidacloprid was 1 and $99 \%$, respectively (Boucias et al., 1996). The ability of termites to protect themselves from pathogenic infection was disturbed by imidacloprid exposure and resulted in improved susceptibility. Collectively, the experiment showed that imidacloprid did not disturb termite cellular defense mechanisms, and additionally explains that social behaviors of termites are their main defense against several pathogenic infections (Boucias et al. 1996). Furthermore, termites treated with imidacloprid held either individually or in groups resulted similar, high rates of mortality after 2 weeks of continuous exposure to soil containing $10^{2}$ to $10^{7}$ conidia/gram (Boucias et al., 1996).

Termiticides used in this study were obtained by using specific formulations of the tested active ingredients. Other formulations with different characteristics under similar test conditions may give different results on subterranean termites. Moreover, field conditions not effectively simulated in laboratory bioassays which may also affect the products not observed in the experiments. Fipronil and imidacloprid may possibly be more useful in controlling termites after they come into contact with treated soil directly. Understanding different ingredients, mobility in soil, their effect on subterranean termites, combination with other ingredients, and other characteristics may help in developing more effective and potential termiticides.

Conflict of Interest. The authors declare no conflict of interest.

\section{References}

Beal, 1986. Field testing of soil insecticides as termiticides. International Research Group on Wood Preservation, Stockholm, Sweden. Document No.IRG-fWpI.1294: 1-9.
Boucias, D.G., Stokes, C., Storey, G., Pendland, J.C. 1996. The effect of imidacloprid on the termite Reticulitermes flavipes and its interaction with the mycopathogen Beauveria bassiana. PflenzenschutzNachrichten Bayer, 49: 103-144.

Changjin, D., Jiamin, Z., Hai, H., Wugwo, C., Yuan yang, H. 2009. Pathogenicity of a new China variety of Metarhizium anisopliae var. dcjhyium to subterranean termite Odontotermes formosans. Microbiological Research, 164: 27-35.

Chouvenc, T., Su, N.Y. 2010. Apparent synergy among defense mechanisms in subterranean termites (Rhinotermitidae) against epizootic events: Limits and potential for biological control. Journal of Economic Entomology, 103: 1327-1337.

Connick, W.J., Osbrink, W.L.A., Wright, M.S., Williams, K.S., Daigle, D.J., Boykin, D.L., Lax, A.R. 2001. Increased mortality of Coptotermes formosanus (Isoptera, Rhinotermitidae) exposed to Eicosanoid biosynthesis inhibitors and Serratia marcescens (Eubacteriales: Enterobacteriaceae). Environmental Entomology, 30: 449-455.

Cowie, R.H., Logan, J.W.M., Wood, T.G. 1989. Termite (isopetra) damage and control in tropical forestry with special reference to Africa and Indo-Malaysia: A review. Bulletin of Entomological Research, 79: 173-184.

Dietrich, C., Brune, A. 2016. The complete mitogenomes of six higher termite species reconstructed from metagenomic datasets (Cornitermes sp., Cubitermes ugandensis, Microcerotermes parvus, Nasutitermes corniger, Neocapritermes taracua, and Termes hospes). Mitochondrial DNA Part A, 27: 39033904.

Forschler, B.T. 1994. Florescent spray paint as a topical marker on subterranean termites (Isoptera: Rhinotermitidae). Sociobiology, 24: 27-38.

Grace, J.K. 1995. Microbial termite control. In: Proceedings of Hawaii Agriculture: Positioning for Growth. College of Tropical Agriculture and Human Resources, University of Hawaii at Manoa. pp. 166-167.

Grace, J.K., Zoberi, M.H. 1992. Experimental evidence for transmission of Beauveria bassiana by Reticuliterimes flavipes workers (Isoptera: Termitidae). Sociobiology, 20: 23-28. 
Grace, J.K., Abdallay, A., Farr, K.R. 1989. Eastern subterranean termite (Isoptera: Rhinotermitidae) foraging territories and populations in Toronto. The Canadian Entomologist., 121: 551-556.

Grimaldi, D., Engel, M.S. 2005. Evolution of the Insects. 145 pp., Cambridge University Press, UK.

Gunner, H.B., Kane, J., Duan, H. 1994. Biological Control of Termites. PCT Patent Application WO94/04034.

Haagsma, K. 2003. Utilization and Movement of Toxicants and Nutrients and their Effects on the Western Subterranean Termite, Reticulitermes hesperus Banks (Isoptera: Rhinotermitidae). pp. 1-143, Ph.D. Dissertation, Department of Entomology, University of California, USA.

Khan, K. 1991. Mycopathogens for biological control of Odonotermes brunneus (Hagen). Journal of Biological Control, 5: 32-35.

Milner, R.J., Staples, J.A. 1996. Biological control of termites-results and experiments within a CSIRO Project in Australia. Biocontrol Science and Technology, 6: 3-9.

Osbrink, W.L.A., Williams, K.S., Connick Jr., W.J., Wright, M.S., Lax, A.R. 2001. Virulence of bacteria associated with the Formosan subterranean termite (Isoptera: Rhinotermitidae) in New Orleans, LA. Environmental Entomology, 30: 443-448.

Rath, A.C. 2000. The use of entomopathogenic fungi for control of termites. Biocontrol Science and Technology, 10: 563-581.

Rath, A.C., Tidbury, C.A. 1996. Susceptibility of Coptotermes acinaciformis (Isoptera: Rhinotermitidae) and Nasutitermes exitiosus (Isoptera: Termitidae) to two commercial isolates of Metarhizium anisopliae. Sociobiology, 28: 67-72.

Rosengaus, R.B., Traniello, J.F.A., Bulmer, M.S. 2010. Ecology, behavior and evolution of disease resistance in termites. In: Biology of Termites: $A$ Modern Synthesis, pp. 165-191, Springer, Dordrecht, Germany.

Rosengaus, R.B., Traniello, J.F.A., Chen, T., Brown, J.J., Karp, R.D. 1999. Immunity in a social insect. Naturewissenschaften, 86: 588-591.

Scharf, M.E., Karl, Z.J., Sethi, A., Boucias, D.G. 2011. Multiple levels of synergistic collaboration in termite lignocellulose digestion. PloS one, 6: e21709.

Sethi, A., Slack, J.M., Kovaleva, E.S., Buchman, G.W., Scharf, M.E. 2013. Lignin-associated metagene expression in a lignocellulose-digesting termite. Insect Biochemistry and Molecular Biology, 43: 91-101.

Smith, J.L., Rust, M.K. 1993. Cellulose and clay in sand affects termiticides treatments. Journal of Economic Entomology, 88: 1690-1694.

Snyder, T.E. 1954. Order Isoptera. The Termites of the United States and Canada. 64 pp., National Pest Control Association, New York, USA.

Song, D., Hu, X.P. 2006. Effects of dose, donor-recipient interaction time and ratio on Fipronil transmission among the Formosan subterranean termite nestmates (Isoptera: Rhinotermitidae). Sociobiology, 48: 1-10.

Su, N.Y., Scheffrahn, R.H. 1990a. Comparison of eleven termiticides against the Formosan subterranean termite and eastern subterranean termite (Isoptera: Rhinotermitidae). Journal of Economic Entomology, 83: 1918-1924.

Su, N.Y., Scheffrahn, R.H. 1990b. Economically important termites in the United States and their control. Sociobiology, 17: 77-94.

Su, N.Y., Tamashiro, M., Yates, J.R., Haverty, M.I. 1982. Effect of behavior on the evalution of incesticides for prevention of or remedial control of the Formosan subterranean termite. Journal of Economical Entomology, 75: 188-193.

Tartar, A., Wheeler, M.M., Zhou, X., Coy, M.R., Boucias, D.G., Scharf, M.E. 2009. Parallel metatranscriptome analyses of host and symbiont gene expression in the gut of the termite Reticulitermes flavipes. Biotechnology for Biofuels, 15: 2-25.

Thorne, B.L., Breisch, N.L. 2001. Effects of sublethal exposure to imidacloprid on subsequent behavior of subterranean termite Reticulitermes virginicus (Isoptera: Rhinotermitidae). Journal of Economic Entomology, 94: 492-498.

Tokuda, G., Tsuboi, Y., Kihara, K., Saitou, S., Moriya, S., Lo, N., Kikuchi, J. 2014. Metabolomic profiling of $13 \mathrm{C}$-labelled cellulose digestion in a lower termite: insights into gut symbiont function. Proceedings of Royal Society of Biological Sciences, 281: 20140990. 
Wells, J.D., Fuxa, J.R., Henderson, G. 1995. Virulence of four fungal pathogens to Coptotermes formosanus (Isoptera: Rhinotermitidae). Journal of Entomology Science, 30: 208-215.

Zoberi, M.H. 1995. Metarhizium anisopliae, a fungal pathogen of Reticulitermes flavipes (Isoptera:
Rhinotermitidae). Mycologia, 87: 354-359.

Zoberi, M.H., Grace, J.K. 1990. Fungi associated with the subterranean termite Reticulitermes flavipes (Kollar) in Ontario. Mycologia, 82: 289-294.

Zoberi, M.H. 1979. The ecology of some fungi in a termite hill. Mycologia, 71: 537-545. 